JURNAL MATEMATIKA. STATISTIKA \& KOMPUTASI

https-//journal.unhas.acid/indexphp/jmsk/index

Vol. 17, No. 2, 155-165, Januaty, 2021

DOI: 10.20956/jmsk.v17i2.11716

\title{
Stability Analysis of Prey-Predator Model With Holling Type IV Functional Response and Infectious Predator
}

\author{
A. Muh. Amil Siddik ${ }^{1 *}$, Syamsuddin Toaha ${ }^{2 *}$, Andi Muhammad Anwar ${ }^{3 *}$
}

\begin{abstract}
Stability of equilibrium points of the prey-predator model with diseases that spreads in predators where the predation function follows the simplified Holling type IV functional response are investigated. To find out the local stability of the equilibrium point of the model, the system is then linearized around the equilibrium point using the Jacobian matrix method, and stability of the equilibrium point is determined via the eigenvalues method. There exists three non-negative equilibrium points, except $E_{0}=(0,0,0)$, that may exist and stable. Simulation results show that with the variation of several parameter values infection rate of disease $\beta$, the diseases in the system may become endemic, or may become free from endemic.
\end{abstract}

Keywords: prey-predator model, disease, Holling response function

\section{INTRODUCTION}

Many researchers have studied the dynamics of populations using mathematical models. The constructed model based on data and real phenomena is believed can be used to predict and give more information qualitatively. Mathematical models related to natural resources and management can be seen for examples in [10], [11], and [12]. Besides that, the mathematical models have also been widely used in investigating the behavior of diseases spread, for example see [3], [8] and [13]. In ecological problems, species populations are very important to study their existence. The existence of the populations is influenced by many factors, two of which are ecological and epidemiological factors. The ecological factors include Intra and interspecies interaction in the form of competition and predation, and epidemiological factors include the spread of infectious disease [7].

Several previous researchers were interested to study the effects of the disease in the predatorprey system. Foryś and Radziński [6] analyzed the diffusive predator-prey system with disease in predator species. They showed that the dynamics of the system mainly depend on the infection rate parameter $\beta$. When the value of $\beta$ is small, there is no positive equilibrium and they expect that the

* Program Studi Matematika, FMIPA-Unhas

Email: 'amilsiddik@unhas.ac.id, ${ }^{2}$ syamsuddint@yahoo.com, 3 andimuhammadanwar08@gmail.com

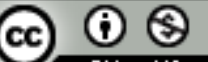

This work is licensed under a Creative Commons Attribution-NonCommercial 4.0 International License. 


\section{A. Muh. Amil Siddik, Syamsuddin Toaha, Andi Muhammad Anwar Jurnal Matematika, Statistika \& Komputasi}

population of infected predators will become extinct. The predator-prey model with parasitic infections that spread only to predator populations in the form of SIS (Susceptible Infected Susceptible) has been reviewed by Haque [5]. The analysis showed that infection with predators can save prey populations from extinction. From the sequence of studies, it can be illustrated that the infection rate affects the prey can still exist in the system.

Besides the spread of disease, interactions between species in an ecosystem cause the state of a species populations can change. These interactions can have a positive, negative or even no effect in the species that interact. To express these phenomena, several researchers tried to understand using an appropriate mathematical method. A suitable mathematical model in ecology cannot be achieved easily because this model could never predict nature's behavior accurately. In facing this major problem, we can search for analyzable model that can be close enough to reality [1]. Andrews proposed a response $\frac{m x}{c+d x+x^{2}}$ called the Monod-Haldane functional response, see [2]. Collings used this function and called it Holling type IV response, see [4]. This response function describes a situation in which the predator's per capita rate of predation decreases at sufficiently high prey densities. Sokol and Howell [9] suggested a simplified Holling type IV function of the form $\frac{w x}{d+x^{2}}$ and found that it is simpler and better than the original function of Holling type IV.

The study aims to determine the effect of the disease in predators to populations in the system, where the predator functional response is based on the simplified Holling type IV. This study using simplified Holling type IV because some investigations about the prey-predators system with the disease, using Holling type II functional response, while few investigations using Holling type IV functional response in population ecology, see [5], [6], and [7]. Furthermore, the conditions for the existence of positive equilibrium points and their stability are analyzed.

\section{ASSUMPTIONS AND MODEL FORMULATION}

\subsection{Assumptions}

The following assumptions are considered in formulating the model:

(1) In the presence of disease, the predator population is divided into two classes, namely susceptible predator and infected predator at time t denoted by $S(t)$ and $I(t)$ respectively. Therefore, at time $t$ the total predator population is denoted as $N(t)=S(t)+I(t)$.

(2) The disease spreads among the predator population only through in-group and out-group interactions and is not genetically inherited. The infected population do not recover or become immune. The incidence function $\beta(N)$ is assumed to be nonlinear function $\beta(N) \equiv 1 / N$, which is a standard incidence.

\subsection{Model Formulation}

The model consisting of prey population density at time $t$ which is denoted by $M(t)$. The susceptible predator population density at time $t$ is denoted by $S(t)$ and the infected predator population density at time $t$ is denoted by $I(t)$. The total population of the predator at time $t$ is denoted by $N(t)$. The susceptible and infected predators prey on the food according to the simplified Holling type IV functional response. 


\section{A. Muh. Amil Siddik, Syamsuddin Toaha, Andi Muhammad Anwar Jurnal Matematika, Statistika \& Komputasi}

The dynamics of the population model can be represented in the form of the differential equations system as the following:

$$
\begin{aligned}
& \frac{d M}{d t}=M(a-b M)-\frac{c M S}{d+M^{2}}-\frac{n M I}{d+M^{2}}: M(0) \geq 0, \\
& \frac{d S}{d t}=\frac{h M S}{d+M^{2}}-\frac{\beta S I}{N}-v S: S(0) \geq 0, \\
& \frac{d I}{d t}=\frac{k M I}{d+M^{2}}+\frac{\beta S I}{N}-(v+\delta) I: I(0) \geq 0, \\
& \frac{d N}{d t}=\frac{h M S+k M I}{d+M^{2}}-\delta I-v N: N(0) \geq 0 .
\end{aligned}
$$

The constants $a, b, c, d, h, k, n, \beta, v, \delta$ in the model (1) are assumed to be positive. The constant $a$ is the growth rate of prey $M$. Constant $b$ represents the intraspecific competition among individuals of prey $M$. Constant $d$ is the half-saturation constant, and $v$ is the predator's natural mortality rate. Constants $c, n$ is the maximum value which per capita reduction rate can $M$ attain. Constants $k, h$ has a similar meaning to $c, n$. Constant $\beta$ is a disease standard incidence disease-induced mortality rate of infected predators.

Let $W$ denote the fractions of susceptible predators and $B$ denote the fractions of infected predators.

If $\frac{S}{N}=W, \frac{I}{N}=B$, then $W+B=1$.

$$
W^{\prime}=\left(\frac{S}{N}\right)^{\prime}=\frac{1}{N}\left(S^{\prime}-\frac{S}{N} N^{\prime}\right), B^{\prime}=\left(\frac{I}{N}\right)^{\prime}=\frac{1}{N}\left(I^{\prime}-\frac{I}{N} N^{\prime}\right) .
$$

The system (1) is then reduced in the form

$$
\begin{gathered}
\frac{d M}{d t}=M\left((a-b M)-\frac{N(c(1-B)+n B)}{d+M^{2}}\right), \\
\frac{d N}{d t}=N\left(\frac{(h(1-B)+k B) M}{d+M^{2}}-\delta B-v\right), \\
\frac{d B}{d t}=B(1-B)\left(\beta-\delta-\frac{(h-k) M}{d+M^{2}}\right) .
\end{gathered}
$$

\section{RESULTS AND DISCUSSIONS}

\subsection{Boundedness}

All of the parameters of the system (2) are non-negative, and so the corresponding right-hand side of the system is a smooth function of the variables $(M, N, B)$ in the region $\Omega$. It follows that local existence and uniqueness properties hold for the solution of the system.

Theorem 1. The region $\Omega=\left\{(M, N, B) \in R_{+}^{3}: 0 \leq M \leq a / b, 0 \leq N \leq N_{1}, 0 \leq B \leq 1\right\}$ is invariant under the flow of the system.

Proof.

1) Consider the system (2), the first equation implies that 


\section{A. Muh. Amil Siddik, Syamsuddin Toaha, Andi Muhammad Anwar Jurnal Matematika, Statistika E Komputasi}

$$
\frac{d M}{d t} \leq M((a-b M))
$$

Because the solution of $\frac{d M}{d t}=M(a-b M)$ is $M(t)=\frac{a}{b+C_{1} a e^{-a t}}$. So $M(t) \leq \frac{a}{b+C_{1} a e^{-a t}}$ and $\lim \sup _{t \rightarrow \infty} M(t) \leq a / b$.

2) From the second equation,

$$
\frac{d N}{d t} \leq N\left(\frac{(h(1-B)+k B) M}{d+M^{2}}-v\right) \leq N\left(\frac{h a}{b}+\frac{k a}{b}-v\right)
$$

with solution $N(t) \leq N_{1} e^{\left(\frac{h a}{b}+\frac{k a}{b}-v\right) t}$ and $\limsup _{t \rightarrow \infty} N(t) \leq N_{1}$ when $(h+k)\left(\frac{a}{b}\right)<v$.

3) From the third equation, it implies that $\frac{d B}{d t} \leq \beta B(1-B)$ with solution $B(t) \leq \frac{D}{D+e^{-\beta t}}$ and $\lim \sup _{t \rightarrow \infty} B(t) \leq 1$.

Any solution with initial values $M_{0}, N_{0}, B_{0}$ eventually approaches this region.

\subsection{Equilibrium points}

The equilibrium points in which prey is present are studied only. There are several nonnegative equilibrium points that can exist.

a) The trivial equilibrium point $E_{0}=(0,0,0)$ always exists.

b) The equilibrium point $E_{1}=\left(\frac{a}{b}, 0,0\right)$ always exists on the boundary of the first octant.

c) $E_{2}=\left(M_{2}, N_{2}, 0\right)$, where $M_{2}$ is positive root of $v M_{2}{ }^{2}-h M_{2}+v d=0, M_{2}$ can be exist when $h^{2}-4 v^{2} d \geq 0, \frac{h}{v}>0$ and $d>0 .(a-b M)=\frac{c S}{d+M^{2}}, N_{2}=\frac{P}{c}$, where $P=$ $\left(a-b M_{2}\right)\left(d+M_{2}^{2}\right), S_{2}$ can be exist if $a>b M_{2}$ or $M_{2}<\frac{a}{b}$.

d) $E_{3}=\left(M_{3}, N_{3}, B_{3}\right)$ exists in the interior of the first octant if only if there is a positive solution to the following equations:

$$
\begin{aligned}
& f_{1}=\frac{d M_{3}}{d t}=\left(a-b M_{3}\right)-\frac{N(c(1-B)+n B)}{d+M^{2}}=0 \\
& f_{2}=\frac{d N_{3}}{d t}=\frac{\left(h\left(1-B_{3}\right)+k B_{3}\right) M_{3}}{d+M_{3}^{2}}-\delta B_{3}-v=0 \\
& f_{3}=\frac{d B_{3}}{d t}=\beta-\delta-\frac{(h-k) M_{3}}{d+M_{3}^{2}}=0
\end{aligned}
$$

The value of $M_{3}$ is the positive root of $(\beta-\delta) M_{3}^{2}-(h-k) M_{3}+\beta d-\delta d=0$. It can be exist when $(h-k)^{2}-4(b-\delta)^{2} d \geq 0, \frac{h-k}{\beta-\delta}>0$, and $d>0 . N_{3}=\frac{\left(a-b M_{3}\right)\left(d+M_{3}^{2}\right)}{c\left(1-B_{3}\right)+n B_{3}}$ exists when $M_{3}<\frac{a}{b}$. And $B_{3}=\frac{v d+v M_{3}^{2}-h M_{3}}{k M_{3}-\delta d-\delta M_{3}^{2}-h M_{3}}$ exists when $v d+v M_{3}^{2}-h M_{3}>0$ and $k M_{3}-\delta d-\delta M_{3}^{2}-h M_{3}$. 


\section{A. Muh. Amil Siddik, Syamsuddin Toaha, Andi Muhammad Anwar Jurnal Matematika, Statistika \& Komputasi}

\subsection{Stability Analysis of Equilibrium Points}

The Jacobian matrix for the system (2) is

$$
J=\left[\begin{array}{ccc}
J 11 & -\frac{M(c(1-B)+n B)}{d+M^{2}} & -\frac{M N(-c+n)}{d+M^{2}} \\
J 21 & \frac{(h(1-B)+k B) M}{d+M^{2}}-\delta B-v & N\left(\frac{(-h+k) M}{M^{2}+d}-\delta\right) \\
J 31 & 0 & J 33
\end{array}\right],
$$

where

$$
\begin{gathered}
J 11=(a-b M)-\frac{N(c(1-B)+n B)}{d+M^{2}}+M\left(-b+\frac{2 M N(c(1-B)+n B)}{\left(d+M^{2}\right)^{2}}\right), \\
J 21=N\left(\frac{h(1-B)+k B}{d+M^{2}}-\frac{2(h(1-B)+k B) M^{2}}{\left(d+M^{2}\right)^{2}}\right), \\
J 31=B(1-B)\left(-\frac{h-k}{M^{2}+d}+\frac{(2(h-k)) M^{2}}{\left(M^{2}+d\right)^{2}}\right), \text { and } \\
J 33=(1-B)\left(\beta-\delta-\frac{(h-k) M}{M^{2}+d}\right)-B\left(\beta-\delta-\frac{(h-k) M}{M^{2}+d}\right) .
\end{gathered}
$$

\subsubsection{Local Stability of $E_{1}=\left(\frac{a}{b}, 0,0\right)$}

Jacobian matrix associated with the the equilibrium point $\boldsymbol{E}_{\mathbf{1}}$ is given by

$$
J_{1}=\left[\begin{array}{ccc}
-a & -\frac{a c}{b\left(d+\frac{a^{2}}{b^{2}}\right)} & 0 \\
0 & \frac{h a}{b\left(d+\frac{a^{2}}{b^{2}}\right)}-v & 0 \\
0 & 0 & \beta-\delta-\frac{(h-k) a}{b\left(d+\frac{a^{2}}{b^{2}}\right)}
\end{array}\right] .
$$

The eigenvalues of matrix $J_{1}$ are $\lambda_{1}=-a, \lambda_{2}=-\frac{b^{2} d v+a^{2} v-a b h}{b^{2} d+a^{2}}$, and

$\lambda_{3}=\frac{b^{2} \beta d-b^{2} d \delta+a^{2} \beta-a^{2} \delta-a b h+a b k}{b^{2} d+a^{2}}$.

Lemma 1. The equilibrium point $E_{1}$ is locally asymptotically stable if the following conditions are satisfied.

a) $a>0$,

b) $b^{2} d v+a^{2} v-a b h>0$, and

c) $b^{2} \beta d-b^{2} d \delta+a^{2} \beta-a^{2} \delta-a b h+a b k$. 


\section{A. Muh. Amil Siddik, Syamsuddin Toaha, Andi Muhammad Anwar Jurnal Matematika, Statistika \& Komputasi}

\subsubsection{Local Stability of $E_{2}=\left(M_{2}, N_{2}, 0\right)$}

Jacobian matrix associated with the the equilibrium point $\boldsymbol{E}_{2}$ is given by

$$
J_{2}=\left[\begin{array}{ccc}
\left(a-b M_{2}\right)-\frac{N_{2} c}{d+M_{2}^{2}}+M_{2}\left(-b+\frac{2 M_{2} N_{2} c}{\left(d+M_{2}^{2}\right)^{2}}\right) & -\frac{M_{2} c}{d+M_{2}^{2}} & -\frac{M_{2} N_{2}(n-c)}{d+M_{2}^{2}} \\
N_{2}\left(\frac{h}{d+M_{2}^{2}}-\frac{2 h M_{2}^{2}}{\left(d+M_{2}^{2}\right)^{2}}\right) & \frac{(h) M_{2}}{d+M^{2}}-v & N_{2}\left(\frac{(-h+k) M_{2}}{M_{2}^{2}+d}-\delta\right) \\
0 & 0 & \beta-\delta-\frac{(h-k) M_{2}}{M_{2}^{2}+d}
\end{array}\right] .
$$

From the matrix $J_{2}$ one knows that one of the eigenvalues is $\beta-\delta-\frac{(h-k) M_{2}}{M_{2}^{2}+d}$. The two other eigenvalues can be determined from the matrix

$$
J_{2}^{*}=\left[\begin{array}{cc}
\left(a-b M_{2}\right)-\frac{N_{2} c}{d+M_{2}^{2}}+M_{2}\left(-b+\frac{2 M_{2} N_{2} c}{\left(d+M_{2}^{2}\right)^{2}}\right) & -\frac{M_{2} c}{d+M_{2}^{2}} \\
N_{2}\left(\frac{h}{d+M_{2}^{2}}-\frac{2 h M_{2}^{2}}{\left(d+M_{2}^{2}\right)^{2}}\right) & \frac{(h) M_{2}}{d+M_{2}^{2}}-v
\end{array}\right] .
$$

The matrix $J_{2}^{*}$ has characteristic polynomial

$$
\lambda^{2}+a_{1} \lambda+a_{2}=0
$$

with $a_{1}=\frac{\left(2 M_{2}^{5} b-M_{2}^{4} a+M_{2}^{4} v+4 M_{2}^{3} b d-M_{2}^{3} h-M_{2}^{2} N_{2} c-2 M_{2}^{2} a d+2 M_{2}^{2} d v+2 M_{2} b d^{2}-M_{2} d h+N_{2} c d-a d^{2}+d^{2} v\right)}{\left(M_{2}^{2}+d\right)^{2}}$

and

$$
\begin{aligned}
a_{2}= & \frac{1}{\left(M_{2}^{2}+d\right)^{2}}\left(2 M_{2}^{5} b v-M_{2}^{4} a v-2 M_{2}^{4} b h+4 M_{2}^{3} b d v+M_{2}^{3} a h-M_{2}^{2} N_{2} c v-2 M_{2}^{2} a d v-\right. \\
& \left.2 M_{2}^{2} b d h+2 M_{2} b d^{2} v+M_{2} a d h+N_{2} c d v-a d^{2} v\right) .
\end{aligned}
$$

All the real parts of solutions of eq. (3) are negative if only if $a_{1}>0$ and $a_{2}>0$.

Lemma 2. The equilibrium point $E_{2}$ is locally asymptotically stable if the following conditions are satisfied.

a) $\beta<\delta+\frac{(h-k) M_{2}}{M_{2}^{2}+d}$,

b) $2 M_{2}^{5} b-M_{2}^{4} a+M_{2}^{4} v+4 M_{2}^{3} b d-M_{2}^{3} h-M_{2}^{2} N_{2} c-2 M_{2}^{2} a d+2 M_{2}^{2} d v+2 M_{2} b d^{2}-$ $M_{2} d h+N_{2} c d-a d^{2}+d^{2} v>0$, and

c) $2 M_{2}^{5} b v-M_{2}^{4} a v-2 M_{2}^{4} b h+4 M_{2}^{3} b d v+M_{2}^{3} a h-M_{2}^{2} N_{2} c v-2 M_{2}^{2} a d v-2 M_{2}^{2} b d h+$ $2 M_{2} b d^{2} v+M_{2} a d h+N_{2} c d v-a d^{2} v>0$.

3.3.3. Local Stability of $E_{3}=\left(M_{3}, N_{3}, B_{3}\right)$

Jacobian matrix associated with the the equilibrium point $\boldsymbol{E}_{\mathbf{3}}$ is given by 


\section{A. Muh. Amil Siddik, Syamsuddin Toaha, Andi Muhammad Anwar Jurnal Matematika, Statistika \& Komputasi}

$$
J_{3}=\left[\begin{array}{ccc}
J 11^{[3]} & -\frac{M_{3}\left(c\left(1-B_{3}\right)+n B_{3}\right)}{d+M_{3}^{2}} & -\frac{M_{3} N_{3}(-c+n)}{d+M_{3}^{2}} \\
J 21^{[3]} & \frac{\left(h\left(1-B_{3}\right)+k B_{3}\right) M_{3}}{d+M_{3}^{2}}-\delta B_{3}-v & N_{3}\left(\frac{(-h+k) M_{3}}{M_{3}^{2}+d}-\delta\right) \\
J 31^{[3]} & 0 & J 33^{[3]}
\end{array}\right],
$$

where

$$
\begin{aligned}
& J 11^{[3]}=\left(a-b M_{3}\right)-\frac{N_{3}\left(c\left(1-B_{3}\right)+n B_{3}\right)}{d+M_{3}^{2}}+M_{3}\left(-b+\frac{2 M_{3} N_{3}\left(c\left(1-B_{3}\right)+n B_{3}\right)}{\left(d+M_{3}^{2}\right)^{2}}\right), \\
& J 21^{[3]}=N_{3}\left(\frac{h\left(1-B_{3}\right)+k B_{3}}{d+M_{3}^{2}}-\frac{2\left(h\left(1-B_{3}\right)+k B_{3}\right) M_{3}^{2}}{\left(d+M_{3}^{2}\right)^{2}}\right), \\
& J 31^{[3]}=B_{3}\left(1-B_{3}\right)\left(-\frac{h-k}{M_{3}^{2}+d}+\frac{(2(h-k)) M_{3}^{2}}{\left(M_{3}^{2}+d\right)^{2}}\right), \text { and } \\
& J 33^{[3]}=\left(1-B_{3}\right)\left(\beta-\delta-\frac{(h-k) M_{3}}{M_{3}^{2}+d}\right)-B_{3}\left(\beta-\delta-\frac{(h-k) M_{3}}{M_{3}^{2}+d}\right) .
\end{aligned}
$$

Let

$$
J_{3}=\left[\begin{array}{ccc}
m 11 & m 12 & m 13 \\
m 21 & m 22 & m 23 \\
m 31 & 0 & m 33
\end{array}\right] .
$$

The characteristic polynomial of $J_{3}$ is

$$
\lambda^{3}+b_{1} \lambda^{2}+b_{2} \lambda+b_{3}=0
$$

where $\quad b_{1}=-(m 11+m 22+m 33), \quad b_{2}=m 11 m 22+m 11 m 33-m 12 m 21+m 22 m 33-$ $m 13 m 31$, and $b_{3}=-m 11 m 22 m 33+m 12 m 21 m 33-m 12 m 23 m 31+m 31 m 13 m 22$.

It is easy to check that If $m 11<0, m 22<0$ and $m 33<0$, then $b_{1}>0$. if $m m 11 m 22+$ $m 11 m 33-m 12 m 21+m 22 m 33-m 13 m 31>0$, then $b_{2}>0$, and if $-m 11 m 22 m 33+$ $m 12 m 21 m 33-m 12 m 23 m 31+m 31 m 13 m 22>0$, then $b_{3}>0$.

From the Routh-Hurwitz criterion, eigenvalue of eq. (4) has negative real parts if $b_{1}>0, b_{2}>0$, and $b_{3}>0$ and $\Delta_{1}=\left|b_{1}\right|>0$ $\Delta_{2}=\left|\begin{array}{cc}b_{1} & b_{3} \\ 1 & b_{2}\end{array}\right|>0$

So, we have $b_{1}>0, b_{2}>0, b_{1} b_{2}-b_{3}>0$.

Lemma 3. The equilibrium point $E_{3}$ is locally asymptotically stable if the following conditions are satisfied.

a. $\left(a-b M_{3}\right)-\frac{N_{3}\left(c\left(1-B_{3}\right)+n B_{3}\right)}{d+M_{3}^{2}}+M_{3}\left(-b+\frac{2 M_{3} N_{3}\left(c\left(1-B_{3}\right)+n B_{3}\right)}{\left(d+M_{3}^{2}\right)^{2}}\right)<0$,

b. $\frac{\left(h\left(1-B_{3}\right)+k B_{3}\right) M_{3}}{d+M_{3}^{2}}-\delta B_{3}-v<0$, and 


\section{A. Muh. Amil Siddik, Syamsuddin Toaha, Andi Muhammad Anwar Jurnal Matematika, Statistika \& Komputasi}

c. $\left(1-B_{3}\right)\left(\beta-\delta-\frac{(h-k) M_{3}}{M_{3}^{2}+d}\right)-B_{3}\left(\beta-\delta-\frac{(h-k) M_{3}}{M_{3}^{2}+d}\right)<0$.

\subsection{Numerical Simulations}

In this section, the dynamical of system (2) is studied and visualized numerically. From the suitable condition of existence equilibrium points, we set following fixed parameters values with appropriate units

$a=0.5 ; b=0.3 ; c=0.27 ; n=0.2 ; h=0.95 ; k=0.7 ; d:=0.5 ; v=0.1 ; \delta=0.02$.

Using initial value $M(0)=0.5, N(0)=0.5$, and $B(0)=0.3$. The dynamical of population for some values of infection rate are done using numerical method rkf45, and system (2) is running for 500 time steps.

The first case, we assume that half of the populations become infected. So $\beta=0.5$.
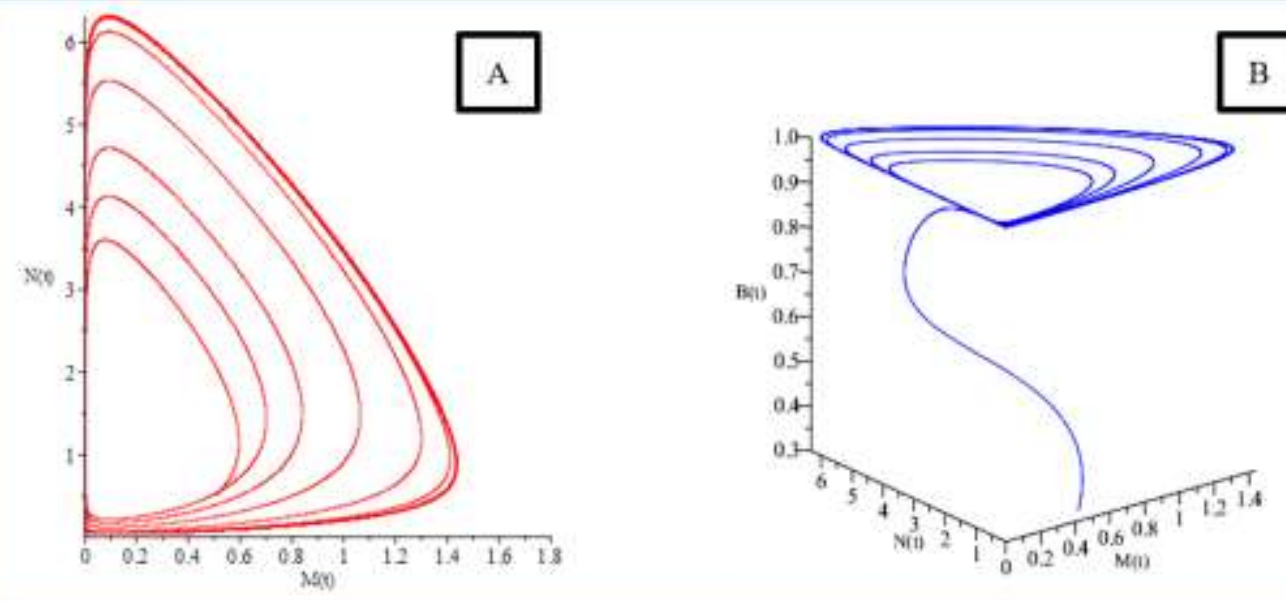

Figure 3. 1 (A) 2D Prey $(\boldsymbol{M}(\boldsymbol{t}))$ vs Predator $(\boldsymbol{N}(\boldsymbol{t}))$ plane of system (2). (B) 3D of the system (2) stable points with data set (5) and $\boldsymbol{\beta}=\mathbf{0 . 5}$.

From Figure 3.1 (A) The populations of prey $M(t)$ and predators $N(t)$ still exist, while when the population of prey $M(t)$ approaches 0 , it needs much time to grow up again. We see from Figure 3.1 (B) the system approaches to $B(t)=1$ (fraction of infected predator $=1$ ), so it means that the system (2) becomes endemic.

When $\beta=0.5, E_{1}, E_{2}$ and $E_{3}$ can be exist. The equilibrium point $E_{1}=(1.67,0,0)$ is not stable, $E_{2}=(0.53,0.9,0)$ is not stable, and $E_{3}=(M=0.08701219228, N=1.202680490, B=$ 1. ) is stable. It means that the system (2) becomes endemic.

The second case, we use $\beta>0.5$ and $\beta<0.5$, but not too small. 


\section{A. Muh. Amil Siddik, Syamsuddin Toaha, Andi Muhammad Anwar Jurnal Matematika, Statistika \& Komputasi}

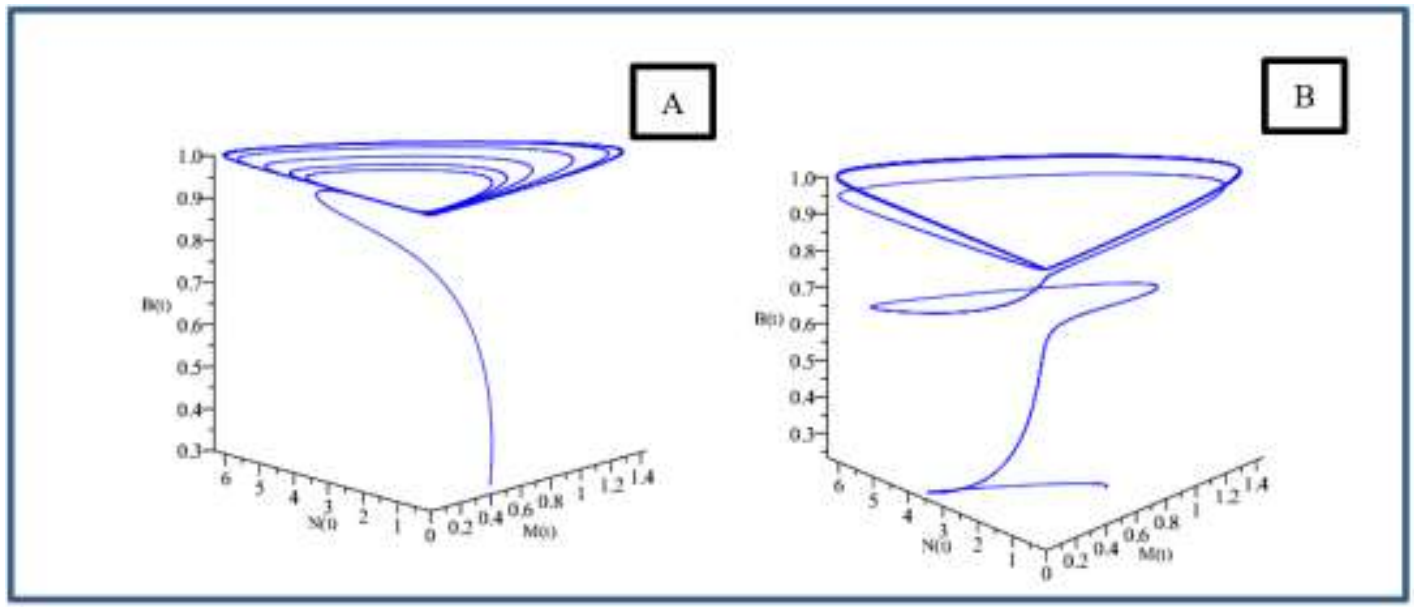

Figure 3. 2 (A) 3D of the system (2) stable points with data set (5) and $\boldsymbol{\beta}=\mathbf{0 . 8}$. (B) 3D of the system (2) stable points with data set (5) and $\boldsymbol{\beta}=\mathbf{0 . 1}$

From the second case, we get $E_{1}$ not stable, $E_{2}$ not stable, and $E_{3}$ stable. It means that the system (2) becomes endemic. This case same as first case. The difference is only seen in the oscillation of the system. See Figure 3.2(A) and Figure 3.2 (B), when $\beta=0.1$ the trajectory goes slower to $B(t)=1$ than $\beta=0.5$.

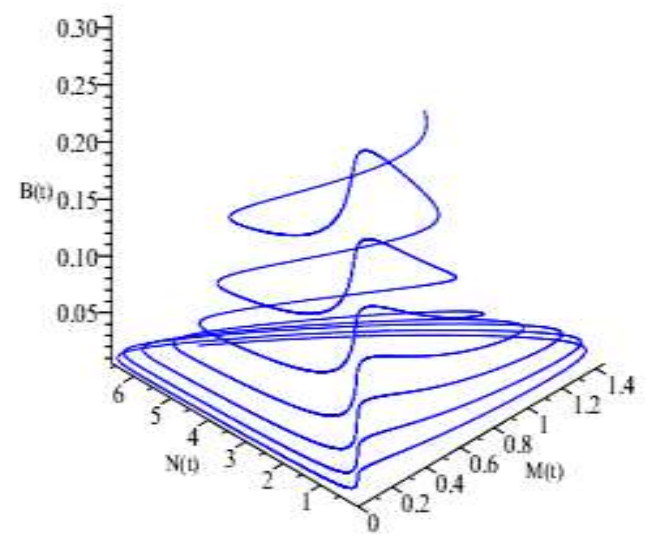

Figure 3. 3 3D of the system (2) stable points with data set (5) and $\boldsymbol{\beta}=\mathbf{0 . 0 4}$.

There are some interesting things that may happen in the third case, when we use small value of $\beta$, say $\beta=0.04$. We get $E_{1}=(1.67,0,0)$ is not stable, $E_{2}=(0.05,0.90,0)$ is stable, and $E_{3}=(0.08,1.2,1)$ is not stable. It means that the system (2) becomes free from endemic with the predators species can still exist, see Figure 3.3. This result is different from Foryś and Radziński 


\section{A. Muh. Amil Siddik, Syamsuddin Toaha, Andi Muhammad Anwar Jurnal Matematika, Statistika \& Komputasi}

[7], which is reported that for a small infection rates, the predator populations become extinct. The condition where the system (2) is free from disease and all populations except $B(t)$ still exists is desired in this study.

\section{CONCLUSION}

The existence and stability of nonnegative equilibrium points of model (2) have been studied in detail. We just studied local stability. From the results and discussion, the conclusions of this study are

1) Any solution with initial values of the system (2) eventually approaches this region $\Omega=\left\{(M, N, B) \in R_{+}^{3}: 0 \leq M \leq a / b, 0 \leq N \leq N_{1}, 0 \leq B \leq 1\right\}$. Where $\Omega$ is invariant under the flow of the system.

2) There are 3 nonnegative equilibrium points which can be existing and locally stable according to condition from Lemma 1, Lemma 2, and Lemma 3.

3) When $\beta=0.1, \beta=0.5$ and $\beta=0.8$, all populations can exist, but the system (2) becomes endemic.

When the value of $\beta$ too small, the system (2) becomes free from endemic, and all of the populations still exist, except the fractions of infected predators. This condition is desired. Even though the prey $M(t)$ needs much time to grow up again if $M(t)$ initially closes to zero.

\section{REFERENCES}

[1] Ali S. J, Arifin N. M., Naji R. K., Ismail F. \& Bachok N., 2016. Analysis of Ecological Model With Holling Type IV Functional Response. Int. J. Pure Apllied Math. Vol. 106, No. 1, 317-31

[2] Andrews, J. F., 1968. A mathematical model for the continuous culture of microorganisms utilizing inhibitory substrates. Biotechnol. Bioeng. Vol. 10, No. 6, 707-723.

[3] Beay L. K., Kasbawati \& Toaha S., 2017. Effects of human and mosquito migrations on the dynamical behavior of the spread of malaria. AIP Conf. Proc. Vol. 1825, 20006

[4] Collings, J. B., 1997. The effects of the functional response on the bifurcation behavior of a mite predator-prey interaction model. J. Math. Biol. Vol. 36, No. 2, 149-168

[5] Haque, M., 2010. A predator-prey model with disease in the predator species only. Nonlinear Anal. Real World Appl. Vol. 11, No. 4, 2224-2236

[6] Radziński, P. \& Foryś, U., 2018. Ananysis of a predator-prey model with disease in the predator species Math. Appl. Vol. 46, No. 1, 137.

[7] Saenz, R. A. \& Hethcote, H. W., 2006. Competing species models with an infectious disease. Math. Biosci. Eng. Vol. 4, No.1, 219-235

[8] Siddik A. M. A., Toaha S. \& Kasbawati, 2017, Kestabilan Model Mangsa Pemangsa dengan Fungsi Respon Holling Tipe Iii Dan Penyakit Pada Pemangsa Super, Prosiding Seminar Nasional Matematika dan Aplikasinya, Surabaya Indonesia, Oktober 16-23.

[9] Sokol, W. \& Howell, J. A., 1981. Kinetics of phenol oxidation by washed cells Biotechnol. Bioeng. Vol. 23, No. 9, 2039-2049

[10] Toaha, S. \& Azis, M. I., 2018. Stability and Optimal Harvesting of Modified Leslie-Gower 


\section{A. Muh. Amil Siddik, Syamsuddin Toaha, Andi Muhammad Anwar Jurnal Matematika, Statistika \& Komputasi}

Predator-Prey Model. J. Phys. Conf. Ser. Vol. 979, No.1, 12069

[11] Toaha, S. \& Rustam, 2017. Optimal harvesting policy of predator-prey model with free fishing and reserve zones. AIP Conf. Proc. Vol. 1825, 1-9.

[12] Toaha S, Kusuma J, Khaeruddin \& Bahri M., 2014. Stability analysis and optimal harvesting policy of prey-predator model with stage structure for predator. Appl. Math. Sci. Vol. 8, No. 157-160, 7923-7934

[13] Wiraningsih E. D., Agusto F., Aryati L., Lenhart S., Toaha S., Widodo \& Govaerts W., 2015. Stability analysis of rabies model with vaccination effect and culling in dogs. Appl. Math. Sci. Vol. 9, No. 77-80, 3805-3817. 